\title{
La protección del patrimonio histórico-artístico durante la Segunda República: Análisis de documentación legal
}

\author{
Lara Nebreda Martín ${ }^{1}$
}

Recibido: 9 de enero 2018 / Aceptado: 28 de mayo de 2018

Resumen. La Segunda República significó un cambio político drástico respecto a la Restauración Borbónica, caracterizado por un gran número de disposiciones legales encaminadas a regular diferentes aspectos relacionados con el arte, la arqueología, la historia y la cultura en general. Así, en este artículo se analiza la legislación relativa a la conservación y protección del patrimonio históricoartístico promulgada desde el comienzo de la Segunda República hasta el inicio de la Guerra Civil (14 de abril de 1931 - 17 de julio de 1936), con especial atención a la Ley 13 de mayo de 1933 y al Decreto 16 de abril de 1936, por el que se aprueba el Reglamento para la aplicación de la mencionada ley. Se analizan también aspectos documentales como la elaboración de catálogos e inventarios y la documentación fotográfica como medidas para preservar el patrimonio cultural español.

Palabras clave: Legislación; Segunda República; Patrimonio; Arte; Arqueología; Comercio de antigüedades.

\section{[en] The protection of historical-artistic heritage during the Second Spanish Republic: Analysis of legal documentation}

\begin{abstract}
The Second Spanish Republic was a drastic political change regarding the Bourbon Restoration, characterize by some legal provisions directed to regulate different aspects related to art, archaeology, history and culture in general. In this article we analyze the legislation relative to the conservation and protection of the historical-artistic heritage promulgated since the Second Republic until the outbreak of the Civil War (April 14, 1931 - July 17, 1936). Special attention is paid to the Law 13 of May 1933 and to the Decree of April 16, 1936, whereby the Regulation for the implementation of the above-mentioned law was approved. It also focuses on documentary aspects, such as the preparation of catalogues and inventories, and the application of photographic documentation as measures to preserve the Spanish cultural heritage.
\end{abstract}

Keywords: Legislation; Second Spanish Republic; Heritage; Art; Archaeology; Antiques trade.

Sumario. 1. Introducción. 2. Legislación relativa el patrimonio durante la Segunda República. 3. Fotografía en la legislación sobre patrimonio de la Segunda República. 4. Aportaciones de la legislación de la Segunda República a la protección del patrimonio. 5. Conclusiones. 6. Referencias bibliográficas. 
Cómo citar: Nebreda Martín, L. (2018) La protección del patrimonio histórico-artístico durante la Segunda República: Análisis de documentación legal, en Revista General de Información y Documentación 28 (1), 213-241.

\section{Introducción}

El objeto de este artículo es recopilar y analizar la legislación relativa al comercio de antigüedades y a la protección y conservación del patrimonio histórico-artístico durante la Segunda República hasta el inicio de la Guerra Civil, tomando como fechas extremas el 14 de abril de 1931, proclamación de este nuevo régimen político, y el 17 de julio de 1936, comienzo de la contienda armada ${ }^{2}$. Este periodo histórico, que supuso un cambio político drástico respecto a la Restauración Borbónica, se caracterizó por un gran número de disposiciones legales encaminadas a regular diferentes aspectos relacionados con el arte, la arqueología, la historia y la cultura en general. Además la elaboración de instrumentos documentales como catálogos e inventarios y el uso de la fotografía se convirtieron en este momento en elementos fundamentales destinados a controlar y proteger el patrimonio español del deterioro natural, pero también de la destrucción intencionada y de las enajenaciones incontroladas que se sucedían de manera reiterada desde principios del siglo XIX.

Con respecto al estado de la cuestión, la legislación relativa al patrimonio histórico-artístico durante la Segunda República se ha estudiado en diferentes publicaciones. La más completa es sin duda "La regulación y la gestión del Patrimonio Histórico-Artístico durante la Segunda República (1931-1939)” de Javier García Fernández (García Fernández, 2007: 1-46), donde se recopilan todas las disposiciones legales relativas a la protección del patrimonio en este periodo concreto, analizando las más importantes y exponiendo además los principales antecedentes aprobados en esta materia desde 1900.

Previamente la Dirección General de Bellas Artes había publicado en 1957 Legislación sobre el Tesoro Artístico de España (Legislación, 1957), obra que presentaba una antología de toda la legislación promulgada desde el siglo XVIII hasta esa fecha, incluyendo las disposiciones legales de la Segunda República. Esta obra, a pesar de ser la más exhaustiva en cuanto a número de normativas recogidas, en realidad no deja de ser una compilación de leyes, decretos, órdenes, etc. sin crítica, ni comentario.

Debemos señalar además que, por su importancia histórica y su dilatada vigencia, la Ley 13 de mayo de 1933 relativa al Patrimonio Artístico Nacional ha sido estudiada por numerosos autores, destacando Gloria González Úbeda en

2 Aunque es cierto que el gobierno republicano continuó su labor legislativa hasta 1939, consideramos que la existencia durante los años que duró el conflicto bélico de dos administraciones diferentes justifica que el límite temporal de nuestro estudio se sitúe en el inicio de la Guerra Civil. En este artículo recogemos la legislación de ámbito nacional, incluyendo algunas disposiciones específicas sobre determinados museos, archivos, bienes inmuebles, municipios... como ejemplos de la actuación de los Gobiernos Republicanos o por su especial interés en el marco legislativo general. Aun así, no es nuestra intención recopilar los decretos específicos, sino aquellos de carácter estatal que regularon el comercio de antigüedades y la protección del patrimonio en este periodo histórico. 
Aspectos jurídicos de la protección del patrimonio histórico-artístico y cultural (González-Úbeda, 1981: 47-53), Mariano del Amo y de la Hera en "Las excavaciones arqueológicas y los museos en la Ley del Patrimonio Artístico Nacional de 1933” (Amo, 1983, 249-267), Concepción Barrero Rodríguez en La ordenación jurídica del Patrimonio Histórico (Barrero, 1990: 73-78), Juan Manuel Alegre Ávila en "El ordenamiento estatal del Patrimonio Histórico Español: Principios y bases de su Régimen Jurídico” (Alegre, 1992: 603-615) y Alfredo Morales Martínez en Patrimonio histórico-artístico: Conservación de bienes culturales (Morales, 1996: 48-49).

Sobre la labor de la Dirección General de Bellas Artes, dirigida durante este periodo principalmente por Ricardo de Orueta, debemos destacar las obras $\mathrm{La}$ política de bienes culturales del Gobierno Republicano durante la Guerra Civil española de José Álvarez Lopera (Álvarez Lopera, 1982); “La Dirección General de Bellas Artes republicana y su reiterada gestión por Ricardo de Orueta (19311936)” y "Ricardo de Orueta, guardián del arte español” de Miguel Cabañas Bravo (Cabañas, 2009: 169-193; Cabañas, 2014: 21-77); "Ricardo de Orueta, la Ley del Tesoro Artístico Nacional de 1933 y los trabajos de conservación del patrimonio arquitectónico de la Dirección General de Bellas Artes durante la Segunda República” de Salvador Guerrero (Guerrero, 2014: 183-193) y "Ricardo de Orueta, un ilustrado patriota del Patrimonio" de Jesús Prieto de Pedro (Prieto, 2014: 289294).

Este artículo se basa además en el capítulo "Comercio y coleccionismo privado de arte y arqueología desde la Restauración a la Segunda República” incluido en La colección de arte y arqueología andalusí del Instituto de Valencia de Don Juan. Análisis y estudio documental (Nebreda, 2018: 148-164), donde, basándonos en las publicaciones anteriormente citadas y en la consulta directa de los textos legales a través de la Gazeta: Colección histórica de la Agencia Estatal del Boletín Oficial del Estado, presentamos un resumen sobre cada una de las disposiciones aprobadas durante la Segunda República, analizando las leyes más importantes y comparándolas con las principales normativas promulgadas en los años previos.

\section{Legislación relativa el patrimonio durante la Segunda República}

\subsection{Legislación de 1931 y 1932}

El 13 de mayo de 1931, apenas un mes después de proclamarse la Segunda República, se modificaba el Reglamento del Museo del Prado por un Decreto que sustituía la normativa de 1920 (García Fernández, 2007: 10). Pocos días después, por Decreto de 22 de mayo, nacía la primera medida importante sobre patrimonio del nuevo régimen, que venía a regular de manera más estricta la venta de objetos artísticos y arqueológicos:

Artículo $1^{\circ}$. Las entidades y personas jurídicas, así eclesiásticas como civiles, no podrán enajenar inmuebles ni objetos artísticos, arqueológicos 
o históricos de una antigüedad que entre los peritos en la materia se considere mayor de cien años, cualesquiera que sean su especie y valor, sin previo permiso del Ministerio de que dependa y mediante escritura pública.

Artículo $2^{\circ}$. Toda entidad o persona jurídica o eclesiástica o civil que quiera enajenar un inmueble o un objeto artístico, arqueológico o histórico lo pondrá en conocimiento del Gobernador Civil de la provincia. Acompañarán a la comunicación dos o más fotografías del inmueble u objeto, su descripción minuciosa con las dimensiones, peso, si el objeto fuese de metal precioso; noticias de su origen e historia, títulos de posesión e indicación precisa de dónde se encuentre el inmueble u objeto además del precio en que está convenida la enajenación [...]

Art. 17. Las personas naturales y las compañías mercantiles dedicadas al comercio de antigüedades quedarán exceptuadas de los preceptos anteriores, salvo en el caso de que estas personas actúen por encargo, comisión o agencia de las comprendidas en el artículo $1^{\circ}$. del presente Decreto $^{3}$.

Además se señalaba que ningún ministerio podría autorizar una enajenación de inmuebles u objetos artísticos o históricos sin haber informado a la Dirección General de Bellas Artes. Según esta normativa las donaciones, permutas o cesiones temporales también quedaban vetadas a menos que la entidad beneficiaria del objeto en cuestión fuera un museo, archivo o biblioteca de España (Legislación, 1957: 241-245).

El Decreto de 26 de mayo de 1931 permitía a la Dirección General de Bellas Artes o al gobernador civil correspondiente incautar obras de arte si sospechaban que su conservación corría peligro. Las piezas requisadas debían depositarse de manera temporal en el museo provincial correspondiente o, en caso de no haberse formado todavía, en alguno de los centros nacionales. El trámite debía completarse con la redacción de un acta donde figurasen los motivos del embargo, el compromiso de que el objeto fuera devuelto cuando las condiciones que amenazaban su integridad cesaran y una detallada descripción del mismo (Legislación, 1957: 245-246).

Unos días más tarde, por Decreto de 29 de mayo de 1931, como medida para fomentar el estudio del patrimonio, se establecía la entrada gratuita a los museos y centros artísticos dependientes del Ministerio de Instrucción Pública y Bellas Artes para los profesores y para los alumnos que acudieran acompañados por maestros (García Fernández, 2007: 11).

El 4 de junio de 1931 se publicaba en la Gaceta de Madrid el listado de los bienes declarados monumentos histórico-artísticos pertenecientes al Tesoro Artístico Nacional. La disposición alcanzaba los 731 inmuebles, incluyendo

Agencia Estatal Boletín Oficial del Estado. Gaceta. Colección histórica. Decreto dictando medidas urgentes y eficaces para la defensa del patrimonio artístico español <http://www.boe.es/datos/pdfs/BOE//1931/143/A00880-00881.pdf>. [Consulta: 17/12/2017]. 
iglesias, monasterios, castillos, palacios, yacimientos, despoblados... (Cabañas, 2009: 174).

El Decreto 3 de julio de 1931, que sufrió una modificación el día 7 del mismo mes, prohibía de manera temporal las exportaciones de objetos valiosos, aunque sí permitía la venta dentro de España entre particulares, siempre que el valor de la pieza no superase las 50.000 pesetas. En caso contrario debía avisarse al gobernador civil correspondiente:

Artículo $1^{\circ}$. Queda temporalmente prohibida la exportación de objetos artísticos, arqueológicos o históricos anteriores a 1830.

Artículo $2^{\circ}$. De las enajenaciones hechas dentro de España cuyo precio sea inferior a 50.000 pesetas, no será necesario dar cuenta al Gobernador Civil $^{4}$.

Una semana después este Decreto se matiza con la Orden Ministerial de 11 de julio de 1931 que explicaba que los objetos de precio inferior a las 50.000 pesetas sí podían salir de España:

Aclara dicho Decreto "en el sentido de que la prohibición de exportar objetos artísticos, arqueológicos o históricos'” a que se refiere su artículo $1 .{ }^{\circ}$, se entenderá que es solo para aquellos cuyo precio de venta sea superior a 50.000 pesetas (Legislación, 1957: 247).

En el mismo mes, se creó el Fichero de Arte Antiguo en el Centro de Estudios Históricos, por Decreto de 13 de julio ${ }^{5}$. Este instrumento debía incluir todas las obras artísticas anteriores a 1850 que se conservaran en España. Igualmente se planificaba crear otro inventario de los bienes que se hubieran exportado o destruido desde 1875 (Legislación, 1957: 247-249; García Fernández, 2007: 11).

Es interesante el artículo $4^{\circ}$ del Decreto, ya que establecía cómo debían formarse los dosieres de cada monumento que se incluyera en el Fichero, utilizando la fotografía como un medio de documentación necesario para estudiar y controlar las obras de arte:

Las Secciones de Arte y Arqueología del Centro de Estudios Históricos procederán a formar un fichero especial de las obras de arte de importancia destruidas o exportadas desde 1875 hasta el día. Cada ficha constará de la fotografía del Monumento u objeto y de cuantos datos sobre el vendedor, intermediarios, precio o precios sucesivos alcanzados, circunstancias de la destrucción o de la enajenación, etc., además del resumen histórico y de la clasificación. Este fichero se publicará por

4 Agencia Estatal Boletín Oficial del Estado. Gaceta. Colección histórica. Decreto aclarando dudas respecto a la prohibición de la exportación de objetos artísticos, arqueológicos o históricos <http://www.boe.es/datos/pdfs/BOE//1931/189/A00211-00211.pdf> [Consulta: 17/12/2017].

5 En el apartado 3. Fotografía en la legislación sobre patrimonio de la Segunda República volveremos a hablar del Fichero de Arte Antiguo. 
artes, por regiones, a expensas del Ministerio de Instrucción Pública y Bellas Artes, y la publicación estará a cargo de las Secciones de Arte y Arqueología del Centro de Estudios Históricos ${ }^{6}$.

En septiembre de 1931, por Decreto del día 1, se creaba el cargo de “Conservador General del Tesoro Artístico Nacional”, puesto ideado especialmente para ser ocupado por el escritor Ramón María del Valle-Inclán, aunque modificado por los Decretos de 27 de enero de 1932 y 8 de marzo de $1933^{7}$.

En el mismo mes, por Decreto del día 15, se declaraba monumento nacional "El Misterio del Siglo XIII", conocido por "Festa de Elche", siendo esta la primera actuación en España en cuestiones sobre protección del patrimonio etnográfico e inmaterial.

Los primeros meses de la Segunda República supusieron además la formación o modificación de la composición de los patronatos y organismos directos del Museo del Prado, Museo de Arte Moderno, Museo Sorolla, Museo Arqueológico Nacional y Museo Nacional de Artes Decorativas. Estos cambios se hicieron efectivos por los Decretos de 13, 27 y 29 de mayo, 3, 10, 17 y 31 de julio, 25 de agosto de 1931 y 6 de octubre de 1931 (Cabañas, 2009: 173-175).

Por la Ley de 23 de octubre de 1931 se crearon además patronatos en el Archivo Histórico Nacional, en el de Indias, Simancas y Corona de Aragón. Además se contemplaba la posibilidad de formar patronatos también en cualquier otro archivo, biblioteca o museo que lo necesitara, compuestos siempre por personas que destacasen por su servicio a la riqueza artística española (García Fernández, 2007: 11) ${ }^{8}$.

También en materia de archivos destaca el Decreto de 12 de noviembre de 1931 que ordenaba la incorporación de los protocolos notariales a los archivos históricoprovinciales o a los archivos históricos de protocolos (García Fernández, 2007: 11). Resulta especialmente interesante el preámbulo que antecede a esta normativa, dictada en realidad por el Ministerio de Justicia, donde se resaltaba la importancia del patrimonio documental, equiparando su relevancia a la de las obras artísticas:

El tesoro documental histórico español, como nuestro tesoro artístico, ha sufrido grandes mermas y daños, aunque más por abandono que por codicia; y si por conservar aquél se han dictado diversas disposiciones y tomado ciertas garantías, justo era también intentar algo para conservar nuestra documentación histórica, teniendo en cuenta que no es difícil recoger y guardar en Archivos esta preciada documentación ${ }^{9}$.

6 Agencia Estatal Boletín Oficial del Estado. Gaceta. Colección histórica. Decreto encomendando a las Secciones de Arte y Arqueología del Centro de Estudios Históricos la formación del Fichero de Arte antiguo que comprenda el inventario de las obras de arte que existen en el territorio nacional anteriores al año 1850 <http://www.boe.es/datos/pdfs/BOE//1931/195/A00382-00383.pdf>. [Consulta: 17/12/2017].

7 Volveremos sobre este asunto en el epígrafe 4.

8 Agencia Estatal Boletín Oficial del Estado. Gaceta. Colección histórica. Ley creando Patronatos directivos e inspectores de los Centros que se indican <http://www.boe.es/datos/pdfs/BOE//1931/298/A0049800498.pdf>. [Consulta: 17/12/2017].

9 Agencia Estatal Boletín Oficial del Estado. Gaceta. Colección histórica. Decreto de 12 de noviembre de 1931 disponiendo que los Protocolos de más de cien años de antigüedad queden incorporados al servicio del Cuerpo 
Así llegamos a la promulgación de la Constitución de la Segunda República el día 9 de diciembre de 1931. El texto constaba de 125 artículos, agrupados en nueve títulos diferentes. Para nuestra investigación, este texto resulta especialmente interesante por ser la primera Constitución española que incluye un apartado dedicado específicamente a lo que hoy podríamos denominar patrimonio nacional:

\section{Artículo 45.}

Toda riqueza artística e histórica del país, sea quien fuere su dueño, constituye tesoro cultural de la Nación y estará bajo la salvaguardia del Estado, que podrá prohibir su exportación y enajenación y decretar las expropiaciones legales que estimare oportunas para su defensa. El Estado organizará un registro de la riqueza artística e histórica, asegurará su celosa custodia y atenderá a su perfecta conservación.

El Estado protegerá también los lugares notables por su belleza natural o por su reconocido valor artístico o histórico ${ }^{10}$.

Al día siguiente se aprobaba la Ley 10 de diciembre de 1931 sobre la enajenación de piezas de más de cien años de antigüedad. Hemos comprobado como desde el primer momento, el gobierno de la República intentó a través de diferentes medidas controlar la venta de obras de arte y arqueología. Una vez promulgada la Constitución, con el apoyo del artículo 45, se recogieron las disposiciones del ya mencionado Decreto de 22 de mayo de 1931 para convertirlos esta vez en ley. Así, podemos destacar que en el artículo 1 se prohibía expresamente la venta de inmuebles u objetos de más de cien años sin previo consentimiento del Ministerio correspondiente, independientemente de si sus propietarios eran particulares, entidades jurídicas, eclesiásticas o civiles. Resulta curioso que según el artículo 17, las entidades dedicadas al comercio de antigüedades quedaban exentas de solicitar esa autorización ministerial siempre que se tratase de meros objetos industriales y de escaso valor artístico, arqueológico o histórico. Esta frase podría interpretarse de manera subjetiva, razón por la que a continuación, en el mismo artículo, se especificaba que el Ministerio podría declarar nulas las operaciones que se ejecutasen sin respetar esta normativa (Legislación, 1957: 8-9 y 250-251).

Resulta interesante también el artículo 19 ya que establecía que mientras no se catalogase lo que denominaba riqueza rústica, su exportación quedaba vetada:

Mientras la riqueza rústica de España, esté sin catalogar queda terminantemente prohibida la exportación de objetos artísticos, arqueológicos e históricos ${ }^{11}$.

facultativo de Archiveros, Bibliotecarios y Arqueólogos para reorganizarlos como archivos históricos <http://www.boe.es/datos/pdfs/BOE//1931/317/A00963-00965.pdf>. [Consulta: 17/12/2017].

10 Congreso de los Diputados: Constituciones Españolas 1812-1978. Constitución de la República Española 9 de diciembre de 1931 <http://www.congreso.es/docu/constituciones/1931/1931_cd.pdf>. [Consulta: 17/12/2017].

11 Agencia Estatal Boletín Oficial del Estado. Gaceta. Colección histórica. Ley relativa a la enajenación de inmuebles, objetos artísticos, arqueológicos e históricos de una antigüedad que, entre los peritos en la materia, 
Esta disposición pretendía evitar las incesantes ventas y expolios que en las décadas anteriores se habían producido en el ámbito rural y que habían supuesto importante pérdidas, como por ejemplo el sorprendente traslado a Estados Unidos del monasterio cisterciense de Sacramenia (Segovia) en $1925^{12}$.

El 1 de febrero de 1932, el director General de Bellas Artes envió una circular a los gobernadores civiles para comunicarles que se había prohibido la colocación de soportes para cables eléctricos o telefónicos en edificios declarados como monumentos y que, además, debían proceder a retirar aquellos que se hubieran instalado anteriormente.

En general el año 1932 se caracterizó por una serie de medidas destinadas a regular el funcionamiento de las bibliotecas. Así, el Decreto de 19 de mayo modificaba la administración del ya centenario Cuerpo de Archiveros, Bibliotecarios y Arqueólogos, reformando la Junta Facultativa del Cuerpo y disponiendo nuevas indicaciones para modernizar las bibliotecas públicas. Unos meses después, por Decreto de 13 de junio se reglamentaban las bibliotecas municipales y por Decreto de 17 de diciembre, las bibliotecas militares (García Fernández, 2007: 11-12, 26-27).

También en 1932, por la Ley de 22 de marzo, se modificaba la naturaleza jurídica de los bienes que habían sido integrantes del Patrimonio de la Corona, convirtiéndose muchos en centros con fines científicos, artísticos, docentes, sanitarios, sociales y turísticos. El funcionamiento de estos organismos fue supervisado por el Ministerio de Hacienda a través de un Consejo de Administración creado ex profeso (Cabañas, 2009: 180).

La Ley de 27 de agosto de este mismo año transformó el Consejo de Instrucción Pública, existente desde 1857, en el Consejo Nacional de Cultura, con la capacidad de emitir dictámenes sobre el Tesoro Artístico e Histórico, incluyendo funciones sobre bibliotecas y museos, ya que, originalmente el Consejo de Instrucción Pública se había centrado más en la educación. Incluso el Gobierno provisional de la República, en un primer momento, siguió contemplándolo como un organismo más vinculado a la formación general que a las bellas artes, tal y como figura en el Decreto 4 de mayo de 1931. Después de la Ley de 27 de agosto, se promulgaron varios decretos destinados a nombrar los consejeros que debían formar parte de la renovada corporación. Realmente su efectividad no fue la esperada y así García Fernández señala explícitamente: No hemos encontrado ninguna actuación de este Consejo en el campo del Patrimonio Histórico (sí en la educación) (García Fernández, 2007: 11-12, 26-27).

se considere mayor de cien años <http://www.boe.es/datos/pdfs/BOE//1931/346/A01635-01636.pdf> . [Consulta: 17/12/2017].

12 Para más información sobre la venta y traslado del monasterio de Sacramenia se puede consultar Martínez Ruiz, 2008: I, 196-206; Merino de Cáceres; Martínez Ruiz, 2012: 68. Para más información sobre los expolios ocurridos durante la Segunda República véase Martínez Ruiz, 2014: 135-163. 


\subsection{Ley de 13 de mayo de 1933 relativa al Patrimonio Artístico Nacional}

Por Decreto de 12 de marzo de 1932 se autorizaba al ministro de Instrucción Pública y Bellas Artes a presentar en las Cortes un proyecto de ley sobre protección del Tesoro Artístico. Después de un año, el 13 de mayo de 1933, se aprobaba la Ley relativa al Patrimonio Artístico Nacional, una de las legislaciones más importantes del siglo XX, que se mantuvo vigente durante más de cincuenta de años. Resulta interesante señalar que Javier García Fernández menciona en su artículo "La regulación y la gestión del Patrimonio Histórico-Artístico durante la Segunda República" que apenas ha localizado información sobre el proceso de tramitación de esta Ley, a pesar de las búsquedas en diferentes archivos y bibliografía de la época ${ }^{13}$.

Siguiendo lo establecido en la Constitución de la República y en la Ley de 20 de diciembre de 1931, el artículo $1^{\circ}$ de la Ley de 13 de mayo de 1933 definía qué objetos se encontraban regulados por esta normativa:

Están sujetos a esta Ley, que cumplimenta lo dispuesto por el artículo 45 de la Constitución y el artículo 18 de la Ley de 10 de diciembre de 1931, cuantos inmuebles y objetos muebles de interés artístico, arqueológico, paleontológico o histórico haya en España de antigüedad no menor de un siglo, también aquellos que sin esta antigüedad tengan un valor artístico o histórico indiscutible, exceptuando, naturalmente las obras de autores contemporáneos; los inmuebles y muebles así definidos constituyen el Patrimonio histórico-artístico nacional.

Resulta interesante el artículo $4^{\circ}$, ya que exponía que el patrimonio documental y bibliográfico debía regularse con una normativa independiente, que realmente no se promulgó hasta casi cuarenta años después, con la Ley de 21 de junio de 1972 sobre el Tesoro Documental y Bibliográfico:

Una Ley especial regulará lo relativo a la conservación de la riqueza bibliográfica y documental de España, quien quiera que sea su poseedor, siempre que no estén al cuidado del Cuerpo Facultativo de Archivos, Bibliotecas y Museos.

El punto siguiente de la Ley de 1933 supone también un hito novedoso en la legislación sobre patrimonio, ya que contemplaba la formación de policías especializados con el objetivo de perseguir las infracciones relacionadas con esta normativa.

13 Para el estudio de esta Ley nos hemos basado en: Legislación, 1957: 251-267; González-Úbeda, 1981: 47-53; Amo 1983: 249-267; Barrero Rodríguez, 1990: 73-78; Alegre Ávila, 1992: 603-615; Morales Martínez 1996: 48-49; García Fernández 2007: 12-16. Los textos citados los hemos obtenido de: Agencia Estatal Boletín Oficial del Estado. Gaceta. Colección histórica. Ley de 13 de mayo de 1933 relativa al Patrimonio Artístico Nacional <http://www.boe.es/datos/pdfs/BOE//1933/145/A01393-01399.pdf>. [Consulta: 17/12/2017]. 
Según los artículos 7 al 13, se creaba y organizaba la Junta Superior del Tesoro Artístico, con la finalidad de garantizar el cumplimiento de esta Ley. Así la Junta quedaba dividida en diferentes secciones temáticas, que facilitaban el control sobre los distintos aspectos regulados por esta normativa: Monumentos históricoartísticos; excavaciones; reglamentación de exportaciones; museos; catálogos e inventarios; y difusión de la cultura artística. Realmente la Junta Superior no tenía poder ejecutivo efectivo, ya que para poder desempeñar cualquier actividad necesitaba la autorización del director general de Bellas Artes.

Se contemplaba además la creación de Juntas locales del Tesoro Artístico en las poblaciones que se considerase adecuado, especialmente en aquellas que se estimasen centros culturales de importancia. Estas Juntas venían a sustituir a las Comisiones Provinciales de Monumentos, que irían desapareciendo según se constituyesen las nuevas corporaciones. Además se establecía que podían formarse igualmente Juntas delegadas, dependientes de la Superior, que se ocupasen de museos, monumentos, centros de enseñanza u otro tipo de instituciones culturales.

El resto de la Ley se articulaba en cinco títulos diferentes, relativos a inmuebles, excavaciones, objetos muebles, museos y al inventario del patrimonio artístico nacional.

En el título primero, artículos del 14 al 36, se establecía que para que los inmuebles o enclaves urbanos o rústicos pudieran acogerse a la protección de esta Ley debían haber sido declarados monumentos histórico-artísticos por decreto, tras presentarse informe favorable de la Real Academia de la Historia, de la Real Academia de Bellas Artes de San Fernando o de la Junta Superior del Tesoro Artístico. Una vez que hubieran alcanzado esa categoría quedaba prohibido su derribo o realizar cualquier tipo de obra sin la autorización de la Junta Superior, que además tenía la potestad de nombrar a los arquitectos de zona y a sus ayudantes, cargos destinados precisamente a la vigilancia de los edificios con características históricas o artísticas. En cualquier caso, los ayuntamientos y diputaciones debían responsabilizarse de la preservación para el fututo de los monumentos nacionales ubicados en sus correspondientes jurisdicciones.

En el caso de las propiedades privadas le correspondía al titular realizar las obras que la Junta Superior estimase necesaria. En caso contrario o de mal uso del inmueble, el Gobierno podía expropiar la edificación. Además se preveía la creación de un censo de edificios en peligro de destrucción, como medida de vigilancia y protección.

El Estado podía expropiar los edificios o propiedades cercanas a un monumento nacional, que impidieran su contemplación o que fueran perjudiciales para la conservación del mismo, cuestión que ya se había contemplado de la misma manera en el Decreto-ley de 1926, anteriormente mencionado.

En el artículo 19 se expresaba el criterio de la República sobre cómo debían realizarse las restauraciones de los inmuebles protegidos, decantándose por prohibir todo intento de reconstrucción; y apostando por la conservación y la reintegración, arreglando solo lo que fuera estrictamente necesario y de tal forma que pudiera distinguirse lo original de aquello reparado después. 
Sobre los edificios declarados monumentos en manos de organismos oficiales, entidades civiles o eclesiásticas, personas jurídicas o particulares, se establecía la obligación para sus dueños de permitir, al menos cuatro veces al mes, la visita, estudio o reproducción fotográfica o por medio de dibujos de los bienes protegidos. En cuanto a su enajenación, se remitía al futuro Reglamento, que finalmente se publicaría en abril de 1936 y del que hablaremos más adelante, aunque ya disponía que en las ventas debía favorecerse la adquisición por parte del Estado y, que, como en ocasiones anteriores, se reservaba el derecho de tanteo.

El título segundo, artículos del 37 al 40, se refería a las excavaciones, aunque sin grandes novedades, ya que expresamente se reconocía la vigencia de la Ley de 7 de julio de 1911 sobre excavaciones artísticas y científicas y sobre la conservación de las ruinas y antigüedades ${ }^{14}$. La única diferencia radicaba en que a partir de la promulgación de la nueva Ley, el máximo organismo responsable pasaba a ser la Junta Superior del Tesoro Artístico.

El tercer título, artículos 41 al 54, correspondía a los bienes muebles declarados como patrimonio nacional y seguía lo estipulado en la Ley de 1931: No podrían cambiarse, ni venderse, ni donarse los objetos protegidos por esta norma que perteneciesen al Estado o cualquier otro órgano de la administración pública, a la Iglesia Católica o a entidades jurídicas. En caso de que la operación se realizase entre estas instituciones, sí podría efectuarse, siempre que se informara a la Junta Superior.

Las empresas mercantiles dedicadas al comercio de antigüedades sí estarían capacitadas para formalizar esos negocios libremente siempre que el valor del material no superase las 50.000 pesetas y respetaran el derecho de tanteo del Gobierno.

En cuanto a las exportaciones de este tipo de bienes, la Ley marcaba lo siguiente en el artículo 43:

No se podrá exportar ningún objeto histórico-artístico sin el permiso de la Sección de Exportaciones de la Junta Superior del Tesoro Artístico. Cuando el valor del objeto sea superior a 50.000 pesetas oro, será necesaria la autorización de la Junta en pleno acordada por mayoría absoluta. En el premiso se hará constar, bajo la responsabilidad de la Sección de Exportaciones o de la Junta en pleno, según los casos, que la salida no cause detrimento al Patrimonio histórico-artístico nacional.

Además se gravaban con unas tasas proporcionales al valor del objeto, aquellos materiales que fueran autorizados para salir de España. También se establecía que incluso para prestar bienes muebles de propiedad pública a otro museo o centro nacional o internacional, era necesaria la autorización del director o del patronato

14 Agencia Estatal Boletín Oficial del Estado. Gaceta. Colección histórica. Ley disponiendo se entiendan por excavaciones, á los efectos de esta Ley, las remociones deliberadas y metódicas de terrenos, respecto á los cuales existan indicios de yacimientos arqueológicos, ya sean restos de construcciones o ya antigüedades<http://www.boe.es/datos/pdfs/BOE/1911/189/A00095-00096.pdf>. [Consulta: 17/12/2017]. 
de la entidad depositaria del objeto y la aprobación del traslado por una disposición ministerial.

En caso de que se ejecutase alguna operación sin cumplir esta legislación, el Estado incautaría la pieza y la destinarían a un museo público. Si el objeto no se pudiera recuperar, las personas involucradas en la venta deberían pagar una multa proporcional al valor del bien perdido.

El artículo 48 otorgaba beneficios fiscales para aquellos coleccionistas que permitieran la visita, estudio y reproducción de sus posesiones:

El propietario de una colección artística, arqueológica o histórica que de manera regular facilite su estudio y su reproducción fotográfica o dibujada, etc., podrá obtener la exención de los derechos reales que en las transmisiones hubiera de pagar por el valor de los objetos que formen su colección.

En cambio, el no respetar esta disposición suponía una multa de hasta el doble de los derechos reales correspondientes a la última transmisión.

El Estado se comprometía además a intentar establecer pactos a nivel internacional con la finalidad de frenar las exportaciones fraudulentas e incentivar la devolución de los bienes que hubieran salido de España, quedando estas importaciones libres de impuestos:

Artículo 53. Queda libre de todo gravamen la importación de objetos de arte de antigüedad mayor de un siglo y los modernos que, a juicio de la Junta Superior del Tesoro Artístico, merezcan ser considerados como acrecentadores del Tesoro artístico nacional.

En el título cuarto, artículos 54 al 65, se presentaban las disposiciones sobre museos, otorgando a la Junta Superior del Tesoro Artístico la capacidad de crear nuevas colecciones públicas y cooperar en la organización y funcionamiento de las ya existentes.

Los museos públicos se configuraban aquí como centros receptores de los bienes privados incautados por peligro para su conservación, por venta o cesión fraudulenta, así como de los objetos descubiertos en excavaciones.

Además el artículo 63 profesionalizaba la labor de conservador, disponiendo que debían crearse escuelas, o al menos cursos prácticos, destinados a formar a personas en la administración, organización y práctica de un museo.

Como en casos anteriores, las donaciones de piezas a centros públicos quedaban exentas de impuestos y el Estado podía expropiar edificios colindantes a un museo si lo consideraba necesario por seguridad o para facilitar el crecimiento de las instalaciones.

El título quinto, artículos del 66 al 72, regulaba la creación del inventario de Patrimonio Artístico Nacional, utilizando como herramientas los Catálogos Monumentales y el Fichero de Arte Antiguo. 
Para el desarrollo de ese inventario se exigía a las corporaciones y entidades, civiles y eclesiásticas, que remitieran los catálogos de sus museos si existían, o una relación de los objetos que se encontraban depositados en sus centros, en un plazo máximo de seis meses. En caso de no cumplir con esta disposición, la Junta Superior estaría capacitada para incautar los objetos y destinarlos a un museo público.

En el artículo 69 de nuevo se insistía en la conveniencia de que cada uno de los registros fuera perfectamente documentado, tanto con información textual como con fotografías de las piezas, bienes o inmuebles.

El artículo 71 hacía referencia a la publicación de los catálogos monumentales ${ }^{15}$, indicando que la Junta Superior se haría responsable de la edición de los volúmenes que faltaban, aprovechando los borradores originales que habían sido entregados, aunque como podemos comprobar en la actualidad, finalmente los ejemplares de varias provincias quedaron inéditos.

La Ley de 1933 terminaba con unos artículos adicionales. Los dos primeros se referían a la financiación de la Junta Superior del Tesoro Artístico:

$1^{\circ}$. La Junta Superior del Tesoro Artístico tendrá como recursos lo que se recaude por derechos de exportación autorizada de objetos antiguos. Los productos de las multas de la exportación fraudulenta, las entradas a los monumentos cuya conservación y sostenimiento sea de su cargo y las cantidades fijadas en los presupuestos del Estado para excavaciones, conservación de monumentos y adquisición de objetos de arte antiguo.

$2^{\circ}$. La Junta Superior del Tesoro Artístico fijará anualmente las subvenciones que hayan de percibir las delegaciones locales, según su importancia y cometido.

La tercera disposición contemplaba que las legislaciones anteriores continuaban vigentes, a excepción de los artículos que contradijeran la presente Ley:

$3^{\circ}$ Quedan subsistentes cuantas disposiciones se hayan dictado para la defensa y acrecentamiento del Patrimonio histórico-artístico nacional en todo lo que no se opongan a las prescripciones de esta Ley ${ }^{16}$.

15 Por Real Decreto de 18 de abril de 1900 se crea el Ministerio Instrucción Pública y Bellas Artes. Una de las primeras medidas aprobadas por este organismo, bajo la dirección de Antonio García Alix, fue la creación de un catálogo monumental de las distintas provincias de España, según se estableció en el Real Decreto de 1 de junio de 1900. A pesar de que los resultados variaron mucho dependiendo de las provincias, los catálogos monumentales supusieron un primer acercamiento al patrimonio histórico artístico de España, destacando especialmente por el uso sistemático de la fotografía como medio para documentar los espacios, objetos y edificios emblemáticos de cada provincia. Actualmente se pueden consultar los Catálogos Monumentales de cada provincia, digitalizados por el CSIC en: Catálogo Monumental de España (1900-1961) $<$ http://biblioteca.cchs.csic.es/digitalizacion_tnt/index.html>. [Consulta: 17/12/2017].

16 Curiosamente en Legislación sobre el Tesoro Artístico de España el texto de la tercera disposición aparece de la siguiente manera: Quedan subsistentes cuantas disposiciones se hayan dictado para la defensa y acrecentamiento del Patrimonio Histórico-Artístico Nacional en todo lo que se oponga a las prescripciones de esta Ley, contradiciendo por completo el sentido de la última cláusula de la Ley de 1933 (Legislación, 1957: 267). 
Como apunte final sobre la legislación de 1933, queremos señalar que se mantuvo vigente durante más de cincuenta años, ya que no fue derogada hasta la Ley 16/1985 de 25 de junio de Patrimonio Histórico Español ${ }^{17}$. En realidad, y como es lógico en un periodo de tiempo tan extenso, esta normativa sufrió varias modificaciones durante su historia que, aunque quedan fueran del margen temporal de este estudio, consideramos adecuado al menos citarlas. Se trata de los Decretos de 12 de junio de 1953, 27 de enero de 1956, 22 de julio de 1958, 23 de septiembre de 1959, 2 de junio de 1960, 11 de julio de 1963, 6 de febrero de 1969, 13 de julio de 1979; y las Leyes 43/1960 de 21 de julio de 1960 y 26/1972 de 21 de junio de 1972 .

\subsection{Otras disposiciones legales promulgadas entre junio de 1933 y julio de 1936}

El Decreto del Ministerio de Instrucción Pública y Bellas Artes de 5 de junio de 1933 exponía que, a pesar de que la Ley de 13 de mayo contemplaba la creación de la Junta Superior del Tesoro Artístico, mientras el funcionamiento de este organismo no fuera establecido por el Reglamento que debía redactarse, se mantendrían la Junta Superior de Excavaciones y el Comité ejecutivo de la Junta de Patronato para Protección y Acrecentamiento del Tesoro Artístico Nacional (Legislación, 1957: 268; García Fernández, 2007: 26).

Por Decreto de 30 de noviembre también de 1933, el gobierno de la República traspasó los servicios de Bellas Artes y conservación de monumentos a la Generalidad de Cataluña, es decir, se transferían las competencias de órganos como la Junta Superior del Tesoro Artístico, las Juntas Delegadas, las Comisiones de Valoración y las Comisiones Provinciales de Monumentos (Legislación, 1957: 269-271; García Fernández, 2007: 19).

En el año 1934 solo encontramos dos disposiciones secundarias. La primera es el Decreto de 13 de marzo por el que se aprobaba el nuevo Reglamento para la organización de exposiciones nacionales de bellas artes. La otra, con carácter local, es el Decreto de 16 de mayo por el que se creaba la Junta de Protección al Madrid Artístico, Histórico y Monumental, con la finalidad de vigilar las reformas que se estaban realizando en el urbanismo de la capital y garantizar la conservación del patrimonio de la ciudad (García Fernández, 2007: 20).

En 1935 se publicó una disposición sumamente proteccionista ya que, según la Orden de 11 de marzo, quedaba prohibido el préstamo para exposiciones nacionales o internacionales de ninguna obra depositada en los museos del Estado, con especial mención de la Pinacoteca del Prado. Tan solo contemplaba que en algún caso excepcional podría accederse al envío de piezas, siempre que el Estado, el patronato o la dirección del museo afectado y la Junta Superior del Tesoro Artístico lo estimasen oportuno (Legislación, 1957: 272).

El 28 de septiembre de 1935 se aprobó un Decreto-Ley con el que se pretendía modificar la administración del Estado, reduciendo cargos y oficinas, como medida

17 Agencia Estatal Boletín Oficial del Estado. Ley 16/1985, de 25 de junio, del Patrimonio Histórico Español <http://www.boe.es/aeboe/consultas/bases_datos/doc.php?id=BOE-A-1985-12534>. [Consulta: 17/12/2017]. 
de austeridad. Precisamente la Dirección General de Bellas Artes fue una de las oficinas suprimidas, pasando sus funciones a una subsecretaría técnica ${ }^{18}$. Consecuencia de los recortes de este Decreto-Ley fue también la aprobación meses después de la Orden del ministro de Instrucción Pública y Bellas Artes de 15 de febrero de 1936 que expresaba que los Cuerpos Facultativo y Auxiliar de Archivos Bibliotecas y Museos quedaban libres de la amortización de plazas establecida en septiembre.

También en febrero de 1936, por Decreto del día 6, se creaba un nuevo Reglamento para las exposiciones nacionales de bellas artes, derogando la normativa establecida apenas dos años antes, en marzo de 1934.

Un día después de las elecciones generales de febrero de 1936, en las que ganó el Frente Popular, se aprobaba el Decreto de 24 de febrero, por el que se restablecía la recién suprimida Dirección General de Bellas Artes (García Fernández, 2007: 16), argumentando que:

Las Bellas Artes no pueden ser para el Gobierno de la República un cúmulo de asuntos administrativos, sino un tema de constante atención. Precisa para ello de un órgano de iniciativas y realización que, a la vez, sirva de enlace con los cuerpos técnicos y asesores - Academias, Junta Superior del Tesoro Artístico, Junta de Archivos, Patronato Nacional de Turismo, Junta de Relaciones Culturales, Patronatos de Museos y Bibliotecas, Entidades establecidas en Cataluña de carácter similar, Asociaciones artísticas, etc., etc. -. Buscando la eficacia máxima de todos los esfuerzos conducentes a la conservación y al conocimiento de los tesoros artísticos del pasado español: al fomento y a la divulgación, dentro y fuera de España, del arte actual y a la formación de futuros cultivadores que sean herederos signos de una tradición artística gloriosa ${ }^{19}$.

El 16 de abril de 1936 se aprobó el Reglamento para la aplicación de la Ley relativa al Patrimonio Artístico Nacional de 13 de mayo de 1933, sobre la que volveremos después.

En junio de 1936, por Orden del ministro de Instrucción Pública y Bellas Artes del día $3^{20}$, se dividía el territorio español en distintos sectores, quedando cada uno de ellos asociado a un arquitecto conservador de zona.

18 Agencia Estatal Boletín Oficial del Estado. Gaceta. Colección histórica. Decreto disponiendo que, a partir de $1^{\circ}$ de Octubre próximo, los Servicios centrales de la Administración, en los diferentes Departamentos ministeriales, serán reorganizados con arreglo a las normas que se publican <http://www.boe.es/datos/pdfs/BOE//1935/272/A02414-02415.pdf>. [Consulta: 17/12/2017].

19 Agencia Estatal Boletín Oficial del Estado. Gaceta. Colección histórica. Decreto restableciendo la Dirección general de Bellas Artes Nacional <http://www.boe.es/datos/pdfs/BOE//1936/056/B01597-01597.pdf>. [Consulta: 17/12/2017].

20 En junio de 1936 el ministro de Instrucción Pública y Bellas Artes era Francisco Barnés Salinas, con Santiago Casares Quiroga como presidente del Gobierno. Agencia Estatal Boletín Oficial del Estado. Gaceta. Colección histórica. Orden señalando las zonas en que ha de ser dividido el territorio nacional y que han de quedar adscritas a los Arquitectos Conservadores de Monumentos < www.boe.es/datos/pdfs/BOE//1936/157/B0205302053.pdf>. [Consulta: 17/12/2017]. 
La última disposición importante que encontramos antes del levantamiento militar que inició la Guerra Civil es la Ley de 5 de junio autorizando al Ministro de Instrucción Pública y Bellas Artes para la ejecución de un plan de obras, excavaciones y adquisiciones de edificios y terrenos con destino a Monumentos del Tesoro Artístico Nacional. Esta medida, que contaba con un presupuesto de casi siete millones de pesetas, finalmente no llegó a aplicarse por el estallido de la contienda bélica en julio de 1936 (Cabañas, 2009: 184).

\subsection{Reglamento de 16 de abril de 1936 para la aplicación de la Ley relativa al Patrimonio Artístico Nacional}

En el mes de abril, por Decreto 16 de abril de 1936, se publicó por fin el amplio Reglamento para la aplicación de la Ley de 13 de mayo de 1933. Su estructura era similar a la de la Ley y no se presentaban grandes novedades sobre lo expuesto entonces.

El capítulo primero se dedicaba a la Junta Superior del Tesoro Artístico y a las Juntas Delegadas, explicando la organización de las mismas y las funciones que debía desempeñar cada cargo. Además se establecía expresamente que, según se formasen las Juntas Delegadas, las antiguas Comisiones de Monumentos irían desapareciendo.

El segundo capítulo correspondía a los monumentos histórico-artísticos sobre los que se especificaba en el artículo 17:

Los monumentos clasificados anteriormente como nacionales o arquitectónicos artísticos y adscritos al tesoro artístico nacional recibirán en adelante la denominación única de monumentos históricos artísticos, debiendo de ser conservados para la nación, correspondiendo tal obligación a sus dueños, poseedores y usufructuarios, ya sean éstos del Estado, Corporaciones provinciales y municipales, entidades de carácter público, fundaciones, patronatos o particulares ${ }^{21}$.

Como ya mencionamos, Concepción Barrero al evaluar la aplicación de la Ley de 1933 criticaba precisamente esta disposición, situándola como uno de los grandes fallos de esta normativa, ya que los propietarios debían sufragar los gastos derivados de la conservación de los bienes, no pudiendo en muchos casos afrontar esos desembolsos y suponiendo por tanto el deterioro de los materiales (Barrero Rodríguez, 1990: 73-78). Es cierto que, teóricamente, todos los objetos considerados patrimonio quedaban bajo la supervisión del Estado y de la Junta Superior del Tesoro Artístico, pero en la práctica, eran los dueños quienes finalmente debían pagar las restauraciones. Así el artículo 23 expresaba:

21 Agencia Estatal Boletín Oficial del Estado. Gaceta. Colección histórica. Decreto del 16 de abril de 1936 por el que se aprueba el Reglamento que se inserta para la aplicación de la Ley del Tesoro Artístico Nacional <http://www.boe.es/datos/pdfs/BOE//1936/108/B00493-00498.pdf>. [Consulta: 17/12/2017]. 
Cuando la Junta Superior del Tesoro Artístico estime, debidamente informada por los Arquitectos de Zona y de los Ayudantes, que es necesario realizar obras imprescindibles de consolidación en un monumento histórico-artístico, de propiedad privada, la Dirección general de Bellas Artes invitará a su propietario o usuario a realizarlas en las condiciones del artículo anterior. Si se negare, la Dirección General de Bellas Artes, a propuesta del Pleno de la Junta Superior del Tesoro Artístico tomado por la mayoría absoluta, procederá a realizarlas. Cuando quede debidamente justificada la carencia de recursos del propietario o usuario, podrá la Dirección general de Bellas Artes, por intermedio de la Junta superior, costear total o parcialmente las obras, conceder un anticipo reintegrable con la garantía del monumento para realizarlas, o incoar el expediente de expropiación por causa de utilidad pública.

De realizarse alguna aportación por el Estado tendrá siempre el carácter de anticipo reintegrable en caso de expropiación, venta o terminación de contrato, constando la inscripción correspondiente del Registro de la Propiedad.

Aun así contemplaba la concesión excepcional de hasta 10.000 pesetas para la realización de obras urgentes en monumentos, aunque sin especificar si los de propiedad privada también podían beneficiarse de esas partidas.

En el artículo 20 se contemplaba por primera vez, la posibilidad de que, tras acuerdo de la sesión plenaria de la Junta Superior, pudieran excluirse bienes del catálogo de monumentos, bien por desaparición o bien por haber perdido el interés que anteriormente supuso su inclusión en ese listado.

Sobre el derribo o desmontaje ilegal de monumentos, también se añadía una nueva cláusula en el artículo 21, que resulta un tanto indulgente:

Cuando un monumento o parte de él haya sido desmontado o derribado clandestinamente, el comprador y vendedor, solidariamente y por partes iguales, quedan obligados a volver a montarlo bajo la dirección de los Arquitectos de Zona.

El artículo 28 contemplaba esta vez que las transmisiones de un edificio declarado monumento podían realizarse libremente, con la única obligación de informar del cambio de titular a la Dirección General de Bellas Artes.

También se incluía la intención de publicar cada dos años la relación de los monumentos declarados histórico-artísticos y se proponía crear otro catálogo con bienes que sin haber sido declarados monumentos, sí presentaran características que justificaban su conservación. La incorporación a este fichero suponía la obligación de los propietarios de avisar a la Dirección General de Bellas Artes cuando fueran a realizar obras de arreglo o mejora en los edificios.

En los artículos 37 al 43 se regulaba la figura y las funciones de los arquitectos conservadores de zona y de los arquitectos ayudantes, que se convertían así en actores de gran importancia en la conservación de los inmuebles declarados como 
patrimonio, al ejercer como asesores y representantes de la Dirección General de Bellas Artes y de la Junta Superior del Tesoro Artístico en cada territorio. Curiosamente, como hemos mencionado, una de las últimas disposiciones que encontramos antes del levantamiento militar de julio de 1936 está relacionada con estos títulos, ya que, por Orden del ministro de Instrucción Pública y Bellas Artes de 3 de junio de 1936, se dividía el territorio de España en distintos sectores, quedando cada uno de ellos asociado a un arquitecto conservador de zona.

El capítulo tercero del Reglamento de 1936 se centraba en las excavaciones arqueológicas, estableciendo en primer lugar que siempre se hallarían bajo el gobierno de la Junta Superior. Se diferenciaba entre las excavaciones costeadas por el Estado y las autorizadas por la Junta, aunque en general se seguían las disposiciones señaladas en la Ley de 1911. Destacaba la decisión de crear un libro de registro de excavaciones donde constasen todas las intervenciones que se estuvieran realizando y unos índices que se describían de la siguiente manera:

Artículo 67. [...] se formarán tres índices: geográfico, cronológico y por materias, en los que consten todos los datos que se conozcan acerca de ruinas y yacimientos de diversa índole que haya en España.

Artículo 68. Los índices serán de papeletas, en las que se describirán todos los yacimientos, despoblados, necrópolis, ruinas, cavernas, pinturas rupestres, monumentos megalíticos, vías y monumentos de todo orden conocidos al presente y que se vayan descubriendo, así como de las antigüedades utilizadas en edificaciones modernas hasta determinar en cada caso la situación topográfica, época o civilización a que correspondan, etc., acompañándose de mapas, planos, fotografías, dibujos y otras reproducciones. [...]

Artículo 70. Como ampliación de los inventarios e índices anteriores se formarán también ficheros que recojan dibujos, fotografías y noticias bibliográficas referentes a las antigüedades de los Museos provinciales, regionales y locales y de colecciones particulares, fijando época y cultura y localidad.

Estas disposiciones resultan especialmente interesantes porque se creaban unas herramientas documentales destinadas, precisamente, a documentar los yacimientos y objetos arqueológicos españoles, incluyendo elementos como la fotografía o la topografía.

El capítulo cuarto trataba de los objetos muebles, centrándose especialmente en los trámites que debían cumplirse para exportar piezas a otros países. La instancia necesaria para tal operación debía incluir los datos básicos de los materiales, la valoración económica y tres fotografías de los mismos, en un nuevo intento por documentar y controlar todos los bienes que salían del país.

El artículo 75 establecía de dónde se obtendría el dinero para que el Estado ejercitara el derecho de tanteo cuando lo considerara oportuno, incluyendo la posibilidad de aceptar capitales privados: 
Para ejercer el derecho de tanto se destinarán los fondos de exportación, la consignación presupuestaria de los fondos y los recursos suministrados por entidades o particulares. Cuando la Junta careciese de recursos podrá estudiar y proponer a la Dirección general de Bellas Artes los medios autorizados por el artículo 45 de la Ley.

El artículo 76 resulta interesante porque era algo novedoso en la legislación ya que permitía la exportación libre, en un plazo de quince años, de los objetos que hubieran sido introducidos en España. Pasado ese tiempo, las piezas se consideraban como existentes en España y se regularían por la legislación habitual.

Los museos ocupaban el capítulo quinto sin variaciones reseñables respecto de lo establecido en la Ley de 1933, tan solo conviene destacar la insistencia en que los museos, fuera cual fuera su titularidad, podían pedir ayuda y asesoramiento a la Sección de Museos de la Junta Superior del Tesoro Artístico.

El sexto capítulo se refería al inventario de patrimonio artístico-histórico y a la difusión de la cultura artística, sin grandes novedades. Destaca otra vez la intención de realizar un inventario del patrimonio histórico-artístico, herramienta que nunca llegó a realizarse, y la inclusión de un nuevo servicio: la Sección de Difusión de la Cultura Artística que tenía como objetivo divulgar cuestiones relacionadas con el arte entre el público general, estudiantes y escolares a través de cursos, conferencias y publicaciones (Legislación, 1957: 272-296; García Fernández, 2007: 14-18).

El Reglamento de 16 de abril de 1936 para la aplicación de la Ley 13 de mayo de 1933, tardó tres años en redactarse pero los resultados fueron una normativa completa, que apenas dejaba resquicios legales y que, sin lugar a dudas, se convirtió en la legislación más eficaz y duradera de cuantas habían existido hasta el momento en cuestión de patrimonio histórico, artístico y cultural.

\section{Fotografía en la legislación sobre patrimonio de la Segunda República}

La fotografía ha sido desde sus inicios una herramienta fundamental para la historia del arte. Así, desde 1838 se utilizó esta técnica en España con fines tanto artísticos como documentales y divulgativos. Claros ejemplos son los trabajos de Laurent o Clifford, quienes en la segunda mitad del siglo XIX fotografiaron monumentos, cuadros, paisajes... creando un material histórico de inestimable valor en la actualidad (Sánchez Vigil 2006: 55).

La primera mención específica al uso oficial de la fotografía como elemento para garantizar la protección del patrimonio histórico-artístico apareció en 1865 en el Reglamento de las Comisiones Provinciales de Monumentos Históricos y Artísticos, Real Orden de 24 de noviembre, publicada en la Gaceta de Madrid de 11 de diciembre de 1865. Así, en el punto 4 del artículo 28 se recomendaba que los trabajos preparados por las diferentes Comisiones se completasen con documentos históricos y diseños o fotografías: 
A la formación de biografías de los pintores, escultores, arquitectos, orfebres y entalladores que más se hubieren distinguido en cada provincia por sus obras artísticas, atendiendo con todo esmero á enriquecerlas con documentos inéditos ó poco conocidos, y á ilustrarlas con diseños ó fotografías de los cuadros, estatuas, relieves ó edificios más notables de cada Profesor ${ }^{22}$.

Desde ese momento, la fotografía continuó contemplándose en la legislación como un recurso necesario para documentar el patrimonio español. Un claro ejemplo es la Real Orden de 22 de mayo de 1916 por la que se exigía que para que un edificio fuera considerado monumento nacional, debían incluirse fotografías en el expediente incoado para conseguir dicho estatus (Legislación, 1957: 140-143; Hernández; López-Yarto, 1998: 110; Nebreda, 2018: 139).

Como hemos podido observar, durante la Segunda República, momento en el que el uso de la fotografía ya se había generalizado en la sociedad española, la presencia de esta técnica como medio de documentación aplicado al patrimonio experimentó un importante auge, convirtiéndose en un aspecto mencionado de manera recurrente en las normativas que se promulgaron entre 1931 y 1936, destacando el Decreto de 22 de mayo de 1931, el Decreto de 13 de julio de 1931, la Ley 13 de mayo de 1933 y el Reglamento de 16 de abril de 1936.

Además de su creciente importancia en la legislación de principios del siglo XX, la creación en 1910 del Centro de Estudios Históricos (CEH) en el seno de la Junta para Ampliación de Estudios e Investigación Científicas (JAE), había contribuido de manera innegable al establecimiento de la fotografía como instrumento esencial para el estudio y el conocimiento del patrimonio histórico español. Así el CEH reunió durante las primeras décadas del siglo XX un importante fondo fotográfico especializado en arte que nutrió con las adquisiciones y donaciones de series y colecciones, los encargos a profesionales o las campañas fotográficas iniciadas desde el propio CEH. Un claro ejemplo es el material fotográfico y documental que se reunió en muchas provincias para la realización del gran proyecto denominado Catálogo Monumental de España ${ }^{23}$.

Con la llegada de la Segunda República, la Dirección General de Bellas Artes, dirigida como ya hemos mencionado por Ricardo de Orueta y Duarte ${ }^{24}$, historiador del arte y aficionado a la fotografía, decidió impulsar un organismo que crease un gran archivo sobre las obras artísticas españolas y sus autores con datos documentales, fotografías, planos... El objetivo principal era catalogar el patrimonio histórico artístico español con la finalidad de frenar los continuos

22 Agencia Estatal Boletín Oficial del Estado. Gaceta. Colección histórica. Real órden aprobando el reglamento para las Comisiones provinciales de Monumentos históricos y artísticos <https://www.boe.es/datos/pdfs/BOE//1865/345/A00001-00001.pdf>. [Consulta: 02/02/2018].

23 Para más información sobre el Catálogo Monumental de España véase: Catálogo Monumental de España $<$ http://biblioteca.cchs.csic.es/digitalizacion_tnt/>. [Consulta: 02/02/2018].

24 Conviene recordar aquí que Ricardo de Orueta y Duarte (Málaga, 1868 - Madrid, 1939) fue director General de Bellas Artes entre abril de 1931 y diciembre de 1933 y entre febrero y septiembre de 1936. Su fondo documental se conserva actualmente en el Archivo del Centro de Ciencias Humanas y Sociales (CCHS) del CSIC (Cabañas, 2009: 170-193). 
expolios que se sucedían desde comienzos del siglo XIX. Con esta premisa nacía por Decreto de 13 de julio de 1931 el Fichero de Arte Antiguo. Su desarrollo se encargó a las secciones de Arte y Arqueología del CEH con la intención de que aprovechasen e incorporasen las imágenes con las que ya contaba este centro. Las funciones de este organismo, como ya hemos mencionado, no se limitaban a la realización del inventario de las obras de arte anteriores a 1850 conservadas en España, sino que se contemplaba la creación de un fichero especial que incluyese las piezas e inmuebles importantes destruidos o expoliados desde 1875, con información histórica y, siempre que fuera posible, documentación fotográfica. El concepto de este Fichero era realmente novedoso, ya que frente a los anteriores inventarios y catálogos en formato libro cerrado, el nuevo instrumento pretendía ser un conjunto de fichas que permitiera un crecimiento lógico de sus fondos y una consulta eficaz de su información, y en las que la fotografía se entendiese como uno de sus elementos fundamentales.

Así, un año después de su creación, se publicó el primer libro preparado en el Fichero de Arte Antiguo, en el que se incluía numeroso material fotográfico procedente de los fondos de esta institución. Recibió el título de Monumentos españoles: Catálogo de los declarados Nacionales, Arquitectónico e HistóricoArtísticos y fue dirigido por Francisco Javier Sánchez Cantón. Su importancia radica en que se concibió como una obra pionera en Europa y convirtió a España en el primer país en aplicar las recomendaciones destinadas a conservar los monumentos arquitectónicos del continente, estipuladas por la Sociedad de Naciones en su reunión de octubre de 1931 en Atenas. El Catálogo inició una línea de publicaciones científicas que continuó manteniéndose durante toda la existencia del CEH. Entre estas obras especializadas de gran relevancia para la época destacan de manera especial la revista Archivo Español de Arte y arqueología y la monumental obra Summa Artis, que se gestó en su seno, utilizando sus recursos documentales y fotográficos.

Debemos destacar que en los primeros años de la Segunda República existían en el CEH seis muebles casilleros con miles de fotografías organizadas y descritas según el sistema ideado por Manuel Gómez-Moreno, modelo que ya había aplicado al Repertorio Iconográfico de Arte Español del Museu Nacional d'Art de Catalunya, creado con motivo de la Exposición Internacional de Barcelona de 1929. Pero además, los presupuestos del CEH muestran los esfuerzos de este centro por incrementar sus fondos fotográficos con nuevas adquisiciones o campañas de investigación. Un claro ejemplo es el material reunido en la primavera de 1932 por Emilio Camps Cazorla, Joaquín María de Navascués y el propio Manuel GómezMoreno durante la excursión universitaria a las zonas francesa y española de Marruecos. En esta línea destacan también los encargos a fotógrafos profesionales como Vicente Moreno de Madrid o la Casa Mas de Barcelona.

Si bien es cierto que el material reunido por el Fichero de Arte Antiguo resulta excepcional como instrumento para el conocimiento y la difusión del patrimonio histórico español, la realidad es que su utilidad para la administración fue prácticamente nula. El organismo que debía garantizar la conservación del patrimonio, el Ministerio de Instrucción Pública y Bellas Artes a través de la 
Dirección General de Bellas Artes, no participaba directamente en el desarrollo del instrumento que debía servir para ese fin y, a pesar de que se estipulaba que existiría una comunicación constante entre ambos organismos, las relaciones mantenidas no lograron impedir el deterioro o pérdida de múltiples objetos artísticos y arqueológicos durante esos años ${ }^{25}$ (Hernández; López-Yarto, 1998: 110-117; Cabañas, 2007: 144-145 y 150-151; Cabañas, 2015: 231-252).

Por otro lado, debemos destacar además que Ricardo de Orueta, como director General de Bellas Artes, promovió la instalación de un laboratorio de fotografía en el Museo Arqueológico Nacional, así como la dotación para una plaza de fotógrafo en la plantilla, puesto que ocupó Aurelio Pérez Rioja. Tanto el laboratorio como el fotógrafo tendrían durante la Guerra Civil un papel fundamental en la documentación gráfica iniciada por la Junta de Incautación y Protección del Patrimonio Artístico, situación que, una vez finalizada la contienda, costó a Pérez Rioja un expediente de depuración y la pérdida de su plaza en el Museo Arqueológico Nacional (Cabañas, 2015: 250).

\section{Aportaciones de la legislación de la Segunda República a la protección del patrimonio}

Los diferentes gobiernos que se sucedieron en el poder entre el 14 de julio de 1931 y el 17 de julio de 1936 promulgaron numerosas disposiciones legales encaminadas a regular aspectos relativos al arte, la arqueología, la historia y la cultura en general. A pesar de los cambios políticos que acontecieron durante este periodo histórico, es destacable que la Dirección General de Bellas Artes, organismo desde el que se promovieron la mayoría de las medidas destinadas a proteger el patrimonio español, estuvo dirigido durante la mayor parte del tiempo por Ricardo de Orueta. Su objetivo principal fue garantizar la conservación del entonces llamado "Tesoro Artístico" mediante la documentación y catalogación de los bienes integrados en esta categoría, finalidad para la que se crearon oficinas administrativas dedicadas a su estudio y preservación.

Si comparamos las medidas promulgadas durante la Segunda República con la legislación anterior, podemos afirmar que, en general, se caracterizaban por su naturaleza sumamente proteccionista, por defender una intervención del Estado más directa y por prestar una mayor atención a las sanciones que debían imponerse por incumplir las normativas desarrolladas en la época. Aun así existen excepciones a esta idea que resultan un tanto anacrónicas: por ejemplo, la Ley 13 de mayo de 1933 en principio imponía límites a la protección privada en favor del Estado, pero a la vez establecía que eran los dueños de los bienes muebles o

25 En este punto conviene señalar que, a finales de 1939, con el nuevo régimen de Francisco Franco, se fundó el Centro Superior de Investigaciones Científicas (CSIC), heredero de la JAE. El anterior CEH pasó a denominarse en 1940 Instituto Diego Velázquez. En aquel momento el Fichero de Arte Antiguo contaba con unas 30.000 fotografías que se convirtieron en el germen del Archivo Fotográfico de Obras de Arte. En la actualidad, tras sucesivos cambios de denominación, el antiguo Fichero se conserva en el Centro de Ciencias Humanas y Sociales del CSIC. 
inmuebles quienes debían garantizar la conservación de sus posesiones, sufragando ellos mismos las obras o restauraciones necesarias para tal fin, algo que en la práctica supuso el deterioro de numerosos edificios y objetos históricos o artísticos.

Sí existió una continuidad con algunos aspectos de las legislaciones anteriores. Por ejemplo, según se especificaba en el Decreto de 22 de mayo de 1931, el Estado se reservaba el derecho de tanteo y la expropiación en caso de incumplirse este Decreto, así como la atribución de imponer multas a quienes no respetasen sus preceptos (Legislación, 1957: 241-245). Esta medida ya se recogía en la Ley de 7 de julio de 1911 sobre excavaciones artísticas y científicas y sobre la conservación de las ruinas y antigüedades y en la Ley de 4 de marzo de 1915, relativa a los monumentos nacionales arquitectónicos artísticos ${ }^{26}$. En cualquier caso, según García Fernández, la finalidad de este Decreto que pretendía regular la venta de objetos artísticos y arqueológicos era intentar impedir que la aristocracia, la burguesía y la Iglesia Católica, más vinculados en principio a la monarquía, intentasen exportar sus bienes artísticos, quedando todo conato de venta bajo la supervisión de la administración pública (García Fernández, 2007: 10).

El título segundo de la Ley de 13 de mayo de 1933, artículos del 37 al 40, se refería como hemos mencionado a las excavaciones arqueológicas, reconociendo expresamente la vigencia de la Ley de 7 de julio de 1911. Se establecía como única diferencia que el máximo organismo responsable era a partir de ese momento la Junta Superior del Tesoro Artístico, creada también por esta misma Ley republicana, y presidida por Ricardo de Orueta desde enero de 1934 hasta junio de 1936, momento en el que fue sustituido en el cargo por Manuel Gómez-Moreno.

La Constitución de la Segunda República, promulgada el 9 de diciembre de 1931, incluía por primera vez un apartado dedicado específicamente a lo que hoy podríamos denominar patrimonio nacional. En la línea de otras legislaciones europeas de la época, establecía un control absoluto del Estado sobre todos los bienes que pudieran considerarse integrantes del patrimonio español, independientemente de quién fuera su propietario. Además, contemplaba la necesidad de crear un inventario de los bienes históricos y artísticos, entendido como un instrumento para proteger y conservar la riqueza del país (García Fernández, 2007: 8-9).

En esta línea, la publicación en la Gaceta de Madrid el 4 de junio de 1931 del listado de los bienes declarados monumentos histórico-artísticos pertenecientes al Tesoro Artístico Nacional supuso un hito importante en la protección del patrimonio. Esta disposición recogía 731 inmuebles, mientras que previamente el número de edificios sujetos a este tipo de amparo apenas superaba los 300 y se restringía a determinadas provincias. Además, por Decreto de 15 de septiembre de

26 Véanse como ejemplos la Ley 7 de julio de 1911 y la Ley de 4 de marzo de 1915: Agencia Estatal Boletín Oficial del Estado. Gaceta. Colección histórica. Ley disponiendo se entiendan por excavaciones, á los efectos de esta Ley, las remociones deliberadas y metódicas de terrenos, respecto á los cuales existan indicios de yacimientos arqueológicos, ya sean restos de construcciones 0 ya antigüedades <http://www.boe.es/datos/pdfs/BOE/1911/189/A00095-00096.pdf>. [Consulta: 17/12/2017] y Agencia Estatal Boletín Oficial del Estado. Gaceta. Colección histórica. Ley relativa a los monumentos nacionales arquitectónicos artísticos <http://www.boe.es/datos/pdfs/BOE/1915/064/A00708-00709.pdf>. [Consulta: 17/12/2017]. 
1931 se declaraba monumento nacional "El Misterio del siglo XIII", conocido por "Festa de Elche", siendo esta la primera actuación en España en cuestiones sobre protección del patrimonio etnográfico e inmaterial (Cabañas, 2009: 173-174; Cabañas, 2015: 240).

Durante este periodo se dictó también la ley más duradera relacionada con la riqueza artística y arqueológica hasta el momento: la Ley de 13 de mayo de 1933, aprobada por Manuel Azaña como presidente del Consejo de Ministros, con Fernando de los Ríos Urruti como ministro de Instrucción Pública y Bellas Artes. Esta normativa había sido preparada por Ricardo de Orueta con el asesoramiento de los mejores especialistas del momento. Su importancia se observa perfectamente en su dilatada vigencia, ya que fue el marco legal de referencia durante el Franquismo, a pesar del radical cambio de régimen político, y aún en los primeros años de la Democracia, hasta que entró en vigor la Ley 16/1985 de 25 de junio de Patrimonio Histórico Español.

Así, en el artículo $1^{\circ}$ de esta Ley, se establecía una limitación temporal de un siglo para los objetos muebles e inmuebles regulados por esta normativa, algo que podría considerarse un paso atrás en relación al anterior Real Decreto-Ley de 9 de agosto de 1926 sobre protección, conservación y acrecentamiento del Tesoro Artístico Nacional ${ }^{27}$. La disposición de 1926 prohibía la exportación de objetos creados antes de 1830, prácticamente el mismo límite que en la Ley de 1933, pero describía con mayor especificidad aquellos bienes posteriores a esa fecha que, al menos teóricamente, también debían conservarse en España. Aun así, es cierto que la Ley de la Segunda República incluía después otros materiales, sin especificar demasiado, que por su especial interés también quedaban protegidos por esta legislación.

Siguiendo con la Ley de 1933, el artículo 19, referido a cómo debían realizarse las restauraciones de los inmuebles protegidos, es también un punto interesante ya que, institucionalmente, se primaba la autenticidad sobre las recreaciones historicistas que tanto habían transformado algunas edificaciones antiguas en las décadas anteriores.

En general esta Ley destaca por la regulación sobre la propiedad privada en favor del Estado, imponiendo límites a un derecho que hasta entonces se consideraba inviolable, y logrando así un mayor control y protección de la administración pública sobre los bienes muebles e inmuebles integrantes del patrimonio nacional. Aun así, Concepción Barrero señala que también tuvo su lado negativo ya que, en la práctica, los propietarios debían responsabilizarse de la conservación de sus posesiones y sufragar ellos mismos las obras necesarias para tal fin, algo que, en muchos casos, supuso el deterioro de los materiales ante la imposibilidad de pagar las inevitables restauraciones (Barrero Rodríguez, 1990: 73-78).

El Reglamento por el que se aplicaba la mencionada Ley se publicó en abril de 1936, siendo una de las últimas normativas promulgadas antes del inicio de la

Agencia Estatal Boletín Oficial del Estado. Gaceta. Colección histórica. Real decreto-ley relativo al Tesoro Artístico Arqueológico Nacional <http://www.boe.es/datos/pdfs/BOE//1926/227/A01026-01031.pdf>. [Consulta: 17/12/2017]. 
Guerra Civil en cuestión de patrimonio. Después de cinco años de medidas proteccionistas, este Reglamento resultó menos restrictivo. Por ejemplo podemos destacar el artículo 20, que permitía que bienes incluidos en el catálogo de monumentos se excluyeran de ese listado por desaparición o por haber perdido el interés que anteriormente supuso su inserción en esta herramienta de control. El artículo 21 resultaba especialmente indulgente, ya que estipulaba que cuando un monumento se hubiera desmontado o derribado sin permiso, el comprador y el vendedor quedaban obligados a erigirlo nuevamente, sin mencionar más sanciones o penas por destruir un bien protegido. El artículo 28 permitía las transmisiones libres dentro de España de edificios declarados monumentos, con la única obligación de informar del cambio de titular a la Dirección General de Bellas Artes. Debemos señalar también que el artículo 76 del Reglamento fue una medida novedosa en la que por primera vez se regulaban los bienes no españoles que se encontraban en territorio nacional, permitiendo su exportación libre durante quince años y estableciendo su sometimiento a la legislación habitual sobre patrimonio después de ese plazo.

Enmarcado en la idea de instrucción y educación de la población, es necesario destacar el trabajo realizado para promover la difusión del patrimonio; así por Decreto de 29 de mayo de 1931, se fijó la entrada gratuita a los centros artísticos dependientes del Ministerio de Instrucción Pública y Bellas Artes para profesores y alumnos. En la misma línea, el sexto capítulo del Reglamento de abril de 1936 se refería a la divulgación de la cultura, mediante la creación de un nuevo servicio: la Sección de Difusión de la Cultura Artística. Este organismo tenía como objetivo familiarizar al gran público con cuestiones relacionadas con el arte a través de cursos, conferencias y publicaciones.

Centrándonos en aspectos documentales, la Segunda República continuó planteando la necesidad de elaborar catálogos e inventarios como medios para proteger el patrimonio. Resulta novedosa la aplicación de manera sistemática de la documentación fotográfica como una herramienta esencial para garantizar el control de los bienes muebles e inmuebles, proyectando incluso la obtención de imágenes de todos los objetos artísticos que se exportaban legalmente en la época.

En este punto debemos destacar la creación por Decreto de 13 de julio de 1931 del Fichero de Arte Antiguo, como un instrumento administrativo dependiente de la Dirección General de Bellas Artes, que pretendía crear un gran archivo sobre las obras de arte españolas y sus autores con datos documentales, fotografías, planos... Como ya hemos mencionado, también se planificaba crear otro inventario de los bienes que se hubieran exportado o destruido desde 1875. Además, durante esta época se alcanzó la equiparación entre el patrimonio documental y el artístico mediante el Decreto de 12 de noviembre de 1931. Por tanto, ya en esta legislación podemos comprobar la importancia de la documentación como una herramienta esencial para el estudio, la conservación y la protección del patrimonio español, incluyendo desde el histórico-artístico hasta el natural o inmaterial.

A pesar de los avances, la gestión desarrollada por el Ministerio de Instrucción Pública y Bellas Artes y por la Dirección General de Bellas Artes también tuvo sus sombras. Especialmente cuestionada fue la política de nombramientos honoríficos 
aplicada durante esta etapa, que terminó por crear inestabilidades en algunas instituciones culturales y descontentos entre personas vinculadas al mundo del arte.

Un claro ejemplo de esta práctica fue la creación por Decreto de 1 de septiembre de 1931 del puesto de "Conservador General del Tesoro Artístico Nacional”. El hombre designado para este cargo fue Ramón María del ValleInclán, quien en aquel momento atravesaba dificultades económicas y se planteaba emigrar a América. Ante esta situación, Manuel Azaña y su Consejo de Ministros decidieron crear una plaza remunerada cuyas funciones variaron para adaptarse a las necesidades del escritor. En realidad, Valle-Inclán apenas se involucró en las labores de información, vigilancia y divulgación del patrimonio que se estipularon en principio para su cargo político, situación que provocó que unos meses después se dictase el Decreto de 27 de enero de 1932, estableciendo que el "Conservador General del Tesoro Artístico Nacional” se ocuparía de la organización y dirección del Museo del Real Sitio de Aranjuez. Finalmente, por Decreto de 8 de marzo de 1933, se designó a Valle-Inclán como director de la Academia Española de Bellas Artes en Roma.

Igualmente, por Decreto de 13 de mayo de 1931 se nombró director del Museo del Prado a Ramón Pérez de Ayala, pero como había sido designado embajador de España en Londres, el Decreto de 18 de mayo de 1931 le reservó la plaza hasta su regreso y estableció que el cargo lo ocuparía de manera provisional Francisco Javier Sánchez Cantón. También por Decreto de 25 de agosto de 1931 se aumentó en dos el número de vocales del Patronato del Museo del Prado, siendo uno de esos puestos para el médico Gregorio Marañón.

Otro centro artístico que se vio afectado por la inestabilidad del cambio de régimen político y las decisiones tomadas por el nuevo gobierno en los primeros meses de la Segunda República fue el Museo de Arte Moderno. Su patronato y dirección dimitieron de forma colectiva hasta en dos ocasiones, incluyendo a su director, el escultor Mariano Benlliure. Los problemas surgidos en torno a este centro se subsanaron en diferentes Decretos (27 de mayo de 1931, 3 de julio de 1931 y 31 de julio de 1931). En cambio, la formación de otros Patronatos, como los del Museo Sorolla, Museo Arqueológico Nacional y Museo Nacional de Artes Decorativas, no plantearon tantas complicaciones (Decretos de 29 de mayo de 1931, 10 de julio de 1931, 17 de julio de 1931 y 6 de octubre de 1931) (Cabañas, 2009: 175).

En cualquier caso, esta política de nombramientos honoríficos a intelectuales destacados en el mundo de la cultura, pero tal vez, poco adecuados para los cargos que se les confiaron provocó el descontento de personas más cercanas al mundo del arte. A la dimisión como director del Museo de Arte Moderno de Mariano Benlliure, se suma la decepción manifestada por el pintor Ignacio Zuloaga, quien después de abandonar la presidencia del Patronato de este mismo centro, declinó aceptar cualquier otro nombramiento oficial del gobierno republicano.

En esta línea, Cabañas Bravo exponía en el artículo "La Dirección General de Bellas Artes republicana y su reiterada gestión por Ricardo de Orueta (1931-1936)” la desilusión del artista Ricardo Baroja expuesta en una carta a Orueta. En esta misiva, además de renunciar a su cargo de Profesor Interino de Tipografía Artística 
en la Escuela de Artes Gráficas, Baroja expresaba con gran acritud su desengaño con el gobierno republicano con las siguientes palabras:

Todo está contribuyendo a mi desilusión republicana. Mi deseo más ferviente es no colaborar con nada del Estado, es más, mi intención es combatirlo con todas mis fuerzas. Se parece a la monarquía esta república, como se parecen dos gotas de agua, algunas veces se parecen como dos gotas de sangres o dos gotas de pus [...]. La República que pone a Pérez de Ayala al frente del Museo del Prado y que ha señalado a Valle-Inclán como posible Director del Museo de Arte Moderno está ya calificada, porque ninguno de los dos sabe una palabra de arte, ni jamás les ha interesado ni la Pintura, ni la Escultura, y los dos han mostrado más palmariamente su incapacidad. Pues lo mismo ocurre con muchos de los nombres para figurar en los Patronatos de los museos ${ }^{28}$.

Como podemos observar, la legislación promulgada durante la Segunda República contribuyó de manera innegable a la formación del concepto de patrimonio que tenemos en la actualidad. Se redactaron numerosos decretos encaminados a garantizar su protección y conservación para las generaciones futuras y, aunque en algunos casos su aplicación resultó tímida y poco eficaz, es indudable que existieron una serie de políticas que pretendían concienciar a la sociedad española de la necesidad de defender y salvaguardar el arte, la arqueología, la cultura y la historia de nuestro país.

\section{Conclusiones}

La Constitución de la Segunda República fue la primera Carta Magna española en incluir un artículo especialmente dedicado al patrimonio, su defensa y conservación por parte del Estado. Podemos entender este reconocimiento como un avance en el cambio de mentalidad que venía gestándose desde finales del siglo XIX, y que enfrentaba a aquellos que consideraban la propiedad privada como un derecho inalienable y a quienes reclamaban una legislación más severa que garantizase la preservación de los bienes culturales para las generaciones futuras.

Entre los progresos iniciados durante este periodo histórico podemos destacar la labor realizada en la creación o modificación de los museos, su gestión y su acceso. A pesar de las polémicas suscitadas en algunos casos, como por ejemplo los nombramientos honoríficos emanados del Ministerio de Instrucción Pública y Bellas Artes, se trabajó por el acceso universal a la cultura, dentro del espíritu formador impulsado por la Institución Libre de Enseñanza.

Las normativas promulgadas durante estos años muestran la valoración de los instrumentos documentales, inventarios, catálogos, fichas... y por supuesto la

28 Cabañas Bravo cita como fuente de este párrafo: Carta fechada en Madrid el 29-VI-1931 (ACCHS, ATOrueta, Caja 1147-3, Exp. 155, 1105-1108) (Cabañas 2009: 174-175). 
fotografía, como herramientas esenciales para garantizar la conservación y protección del patrimonio. Los diferentes gobiernos intentaron a través de diversos decretos crear un inventario completo de los bienes histórico-artísticos españoles, objetivo que, a pesar de los esfuerzos dedicados, nunca terminó de alcanzarse, quedando las sucesivas tentativas en proyectos inacabados, sin validez real. En cambio, sí podemos considerar un éxito el incremento del uso de la fotografía en las labores de documentación de los objetos considerados valiosos. Es cierto que la fotografía ya se había generalizado en la sociedad española en la década de los años 30 del siglo XX y que esta situación sin duda contribuyó a su utilización sistemática en las labores de defensa del patrimonio, aun así merece una especial mención la labor de realización, adquisición, recopilación y catalogación de material fotográfico desarrollada por el Fichero de Arte Antiguo, en el seno del CEH.

Para finalizar debemos insistir nuevamente en la importancia legal e histórica de la Ley de 13 de mayo de 1933 relativa al Patrimonio Artístico Nacional, normativa que se mantuvo vigente hasta su derogación por la Ley 16/1985 de 25 de junio de Patrimonio Histórico Español, convirtiéndose en una de las legislaciones más longevas y efectivas en cuestión de defensa del patrimonio hasta el momento actual.

Las disposiciones legales proyectadas durante la Segunda República supusieron un avance respecto a las normativas previas, especialmente en el desarrollo del concepto de patrimonio tal y como lo entendemos hoy en día y en su regulación como un elemento esencial para el Estado Español. En esta línea destacan de manera especial la equiparación del patrimonio documental al artístico y las primeras medidas destinadas a defender el patrimonio inmaterial y etnográfico. Aun así, debemos reconocer que se percibe timidez en algunas medidas o en su aplicación, como se desprende de la comparación entre la Ley de 1933 y el Reglamento de 1936, pero en cualquier caso estas disposiciones contribuyeron de manera innegable a establecer la idea de que los bienes histórico-artísticos españoles deben protegerse y conservarse, contemplando además la necesidad de crear una conciencia social que garantice su preservación para las generaciones futuras.

\section{Referencias bibliográficas}

Agencia Estatal Boletín Oficial del Estado. Gaceta. Colección histórica <www.boe.es/buscar/gazeta.php>. [Consulta: 17/12/2017].

Alegre Ávila, J.M. (1992). El ordenamiento estatal del Patrimonio Histórico Español: Principios y bases de su Régimen Jurídico. Revista de estudios de la administración local y autonómica, 255-256, 599-642.

Álvarez Lopera, J. (1982). La política de bienes culturales del Gobierno Republicano durante la Guerra Civil española. Madrid: Ministerio de Cultura.

Amo y de la Hera, M. del (1983). Las excavaciones arqueológicas y los museos en la Ley del Patrimonio Artístico Nacional de 1933. Boletín de la ANABAD, 2, 249-267.

Barrero Rodríguez, C. (1990). La ordenación jurídica del Patrimonio Histórico. Madrid: Civitas.

Cabañas Bravo, M. (2007). La Historia del Arte en el Centro de Estudios Históricos de la JAE, en Tiempos de investigación: JAE-CSIC, cien años de ciencia en España. Madrid: CSIC, 143-151. 
Cabañas Bravo, M. (2009). La Dirección General de Bellas Artes republicana y su reiterada gestión por Ricardo de Orueta (1931-1936). Archivo Español de Arte, 82 (326), 169193.

Cabañas Bravo, M. (2014). Ricardo de Orueta, guardián del arte español, en En el frente del arte: Ricardo de Orueta 1868-1939. Madrid: Acción Cultural Española, AC/E, 21-78.

Cabañas Bravo, M. (2015). El Fichero de Arte Antiguo de 1931, fondo fotográfico e instrumento administrativo para el estudio y protección del arte, en El arte y la recuperación del pasado reciente. Madrid: CSIC, 231-252.

Congreso de los Diputados: Constituciones Españolas 1812-1978. Constitución de la República Española 9 de diciembre de 1931 <www.congreso.es/docu/constituciones/ 1931/1931_cd.pdf> [Consulta: 17/12/2017].

García Fernández, J. (2007). La regulación y la gestión del Patrimonio Histórico-Artístico durante la Segunda República (1931-1939). E-rph: Revista electrónica de Patrimonio Histórico, 1, 1-46.

González-Úbeda Rico, G. (1981). Aspectos jurídicos de la protección del patrimonio histórico-artístico y cultural. Madrid: Ministerio de Cultura.

Guerrero López, S. (2014). Ricardo de Orueta, la Ley del Tesoro Artístico Nacional de 1933 y los trabajos de conservación del patrimonio arquitectónico de la Dirección General de Bellas Artes durante la Segunda República, en En el frente del arte: Ricardo de Orueta 1868-1939. Madrid: Acción Cultural Española, AC/E, 183-193.

Hernández Núñez, J.C.; López-Yarto Elizalde, Amelia (1998). El Fichero de Arte Antiguo y la Fototeca del Departamento de Arte "Diego de Velázquez" del Centro de Estudios Históricos (CSIC). Boletín del Instituto Andaluz del Patrimonio Histórico, 22, 110-117.

Legislación sobre el Tesoro Artístico de España (1957). Madrid: Dirección General de Bellas Artes.

Martínez Ruiz, M.J. (2008). La enajenación del patrimonio en Castilla y León (19001936). Valladolid: Consejería de Cultura y Turismo.

Martínez Ruiz, M.J. (2014). “Orueta y su actuación frente a la pérdida del patrimonio”, en El arte y la recuperación del pasado reciente. Madrid: CSIC, 135-163.

Merino de Cáceres, J.M.; Martínez Ruiz, M.J. (2012). La destrucción del patrimonio artístico español: W.R. Hearst: “El gran acaparador”. Madrid: Cátedra.

Morales Martínez, Alfredo José (1996). Patrimonio histórico-artístico: Conservación de bienes culturales. Madrid: Historia 16.

Nebreda Martín, L. (2018). Comercio y coleccionismo privado de arte y arqueología desde la Restauración a la Segunda República, en La colección de arte y arqueología andalusí del Instituto de Valencia de Don Juan. Análisis y estudio documental. Madrid: Real Academia Matritense de Heráldica y Genealogía.

Prieto de Pedro, J.J. (2014). Ricardo de Orueta, un ilustrado patriota del Patrimonio. Patrimonio cultural y derecho, 18, 289-294.

Sánchez Vigil, J.M. (2006). El documento fotográfico: Historia, usos, aplicaciones. Gijón: Trea. 